\title{
Analysis on Binding Energy and Auger Parameter for Estimating Size and Stoichiometry of ZnO Nanorods
}

\author{
Santanu Bera, ${ }^{1}$ Sandip Dhara, ${ }^{2}$ S. Velmurugan, ${ }^{1}$ and A. K. Tyagi $^{2}$ \\ ${ }^{1}$ Water and Steam Chemistry Division, BARC Facilities, Kalpakkam 603 102, India \\ ${ }^{2}$ Surface and Nanoscience Division, IGCAR, Kalpakkam 603 102, India \\ Correspondence should be addressed to Sandip Dhara, dhara@igcar.gov.in
}

Received 26 May 2011; Revised 24 June 2011; Accepted 9 August 2011

Academic Editor: Alexander Milekhin

Copyright ( $) 2012$ Santanu Bera et al. This is an open access article distributed under the Creative Commons Attribution License, which permits unrestricted use, distribution, and reproduction in any medium, provided the original work is properly cited.

\begin{abstract}
$\mathrm{ZnO}$ nanorods prepared through chemical vapor deposition technique are characterized by microscopic and X-ray photoelectron spectroscopy (XPS) techniques to correlate the effects of size on the binding energy of $\mathrm{Zn} 2 \mathrm{p}_{3 / 2}$ photoelectrons. A positive shift in $\mathrm{Zn} 2 \mathrm{p}_{3 / 2}$-binding energy as compared to that in bulk $\mathrm{ZnO}$ is assumed to be the effect of size of $\mathrm{ZnO}$ tips. The shift in binding energy has been explained in terms of relaxation energy in the photoemission process. Simultaneously, Auger parameter of the nanorods is evaluated for stoichiometric composition. The extra peak in O1s spectrum of nanorods is explained as adsorbed O-bearing species or surface contaminants.
\end{abstract}

\section{Introduction}

One-dimensional (1-D) nanostructures of semiconducting materials have received much attention in recent years, with the expectation that they can be applied to short-wavelength optical devices and excitonic devices operating at room temperature. In particular, the exciton-binding energies in $\mathrm{GaN}$ and $\mathrm{ZnO}$ are reported so large that they can be applied to laser devices based on excitonic processes. In fact, excitonrelated stimulated emission and optically pumped laser action in $\mathrm{GaN}$ and $\mathrm{ZnO}$ nanostructures have been observed at room temperature $[1,2]$. Its high band gap energy of $3.37 \mathrm{eV}$ at room temperature [3] and free-exciton binding energy $(60 \mathrm{meV})$ [2] which is much larger than that of GaN $(\sim 25 \mathrm{meV})[1]$ along with its larger absorption coefficient compared to $\mathrm{GaN}$ make $\mathrm{ZnO}$ a potential candidate for optoelectronics applications. A detailed photoluminescence (PL) study at low temperature with assignments of excitonic peaks and associated longitudinal optical (LO) phonon replicas along with donor-pair-acceptor transitions has been reported for $\mathrm{ZnO}$ single crystalline sample [4]. Looking at the importance in the understanding of electronic properties for the ultimate optoelectronic applications, a study on the effect of size dispersion on electronic properties will be extremely important.
We report here the photoelectron spectroscopic studies of stoichiometric $\mathrm{ZnO}$ nanorods (NRs), grown by catalystfree chemical vapor deposition (CVD) technique, with sharp facets. Role of size in these nanostructure on the binding energy of photoelectrons is studied in the light of final state effects of the photoemission process.

\section{Experimental Details}

$\mathrm{ZnO}$ NRs were grown on $p^{++}-\mathrm{Si}(\sim 0.001 \mathrm{Ohm}-\mathrm{cm})$ substrate in the flow of $\mathrm{N}_{2} / \mathrm{O}_{2}(500 \mathrm{sccm})$ at $130-140^{\circ} \mathrm{C}$ by CVD technique using metalorganic precursor of zinc bisacetylacetonate hydrate $\left[\mathrm{Zn}(\mathrm{AA})_{2} \cdot x \mathrm{H}_{2} \mathrm{O} ; \mathrm{Zn}\left(\mathrm{C}_{5} \mathrm{H}_{7} \mathrm{O}_{2}\right)_{2} \cdot x \mathrm{H}_{2} \mathrm{O}\right.$ ] [5]. The morphology of the NRs was studied using field emission scanning electron microscopy (FESEM; M/S Carl Zeiss, Model Supra 55).

X-ray photoelectron spectroscopy (XPS) studies were carried out in an ultrahigh vacuum chamber fitted with dual $\mathrm{X}$-ray sources (VG ESCA LAB MKII). Al K $\alpha$ was used as the exciting source $(1486.6 \mathrm{eV})$ of photoelectrons, and a hemispherical analyzer $(150 \mathrm{~mm}$ diameter) was used for energy analysis. The pass energy for the high-resolution scan was kept at $20 \mathrm{eV}$. The spectrometer was calibrated by recording the binding energy of $\mathrm{Au} 4 \mathrm{f}_{7 / 2}$ peak at $83.9 \mathrm{eV}$. C1s peak at $284.6 \mathrm{eV}$ was taken as an internal standard for correcting 
TABLE 1: Binding energy and modified Auger parameter (m-AP) obtained from different samples.

\begin{tabular}{lcccc}
\hline Sample & $\begin{array}{c}\text { Zn 2p } \mathrm{p}_{3 / 2} \\
(\mathrm{FWHM}) \\
\mathrm{eV}\end{array}$ & $\begin{array}{c}\mathrm{Zn} \mathrm{L}_{3} \mathrm{M}_{45} \mathrm{M}_{45} \\
(\text { Kinetic energy }) \\
\mathrm{eV}\end{array}$ & $\begin{array}{c}\mathrm{m}-\mathrm{AP} \\
\left(\alpha^{\prime}\right) \\
\mathrm{eV}\end{array}$ & $\begin{array}{c}\mathrm{O} 1 \mathrm{~s} \\
(\mathrm{FWHM}) \\
\mathrm{eV}\end{array}$ \\
\hline ZnO NRs & $1022.1(1.9)$ & 988.3 & 2010.4 & $\begin{array}{c}529.9(1.6) \\
531.9(2.9)\end{array}$ \\
ZnO Bulk & $1021.6(1.9)$ & 988.8 & 2010.4 & $529.9(1.6)$ \\
ZnO Bulk [6] & 1021.7 & & 2010.5 & \\
\hline
\end{tabular}

the shift in binding energy peaks due to charging of the samples which was amounting to $3.9 \mathrm{eV}$ for nanorods and $0.8 \mathrm{eV}$ for the bulk powder. The accuracy of measurement of the binding energy is $\pm 0.1 \mathrm{eV}$ and uncertainty $\leq 0.2 \mathrm{eV}$.

\section{Results and Discussion}

3.1. Morphological Studies. FESEM images show well-aligned NRs with diameters $\sim 100 \mathrm{~nm}$ (for different orientations in Figure 1) grown using CVD technique. Structural details including small facets $\sim 5-10 \mathrm{~nm}$ of the aligned NRs are reported elsewhere [5].

3.2. Photoelectron Spectroscopic Studies. Detailed XPS analyses on $\mathrm{ZnO}$ NRs and bulk $\mathrm{ZnO}$ powder were carried out by recording $\mathrm{Zn} 2 \mathrm{p}, \mathrm{O} 1 \mathrm{~s}$, and $\mathrm{Zn}$ LMM Auger lines. The photoelectron spectra from bulk $\mathrm{ZnO}$ powder were taken as reference peaks of $\mathrm{Zn} 2 \mathrm{p}$ or O1s and compared with those obtained from NRs prepared by the above method.

3.2.1. Modified Auger Parameter. Modified Auger parameter is an important energy parameter for identifying the chemical state of elements where chemical shift is very small or comparable with the energy resolution of the instrument. The chemical shift of $\mathrm{Zn} 2 \mathrm{p}_{3 / 2}$ peak is very small in $\mathrm{ZnO}$ and thus is difficult to identify the chemical state of $\mathrm{Zn}$ in $\mathrm{ZnO}$. Finding modified Auger parameter $\left(\alpha^{\prime}\right)$ can be an ideal method to get the chemical state and stoichiometry of $\mathrm{ZnO}$ NRs. In principle, the parameter is calculated by adding the binding energy of the most intense photoelectron peak with the kinetic energy of the sharpest Auger peak. For $\mathrm{ZnO}$ samples, the Auger parameter was calculated by taking the binding energy of $Z n 2_{3 / 2}$ photoelectron peak and kinetic energy of $\mathrm{Zn} \mathrm{L}_{3} \mathrm{M}_{45} \mathrm{M}_{45}$ Auger peak (Table 1).

3.2.2. Analysis on $Z n$ 2p $3 / 2$ Photoelectron Peak. In Figure 2, the $\mathrm{Zn} 2 \mathrm{p}_{3 / 2}$ peak obtained from $\mathrm{ZnO}$ NRs is compared with that from bulk $\mathrm{ZnO}$. The $\mathrm{Zn} 2 \mathrm{p}_{3 / 2}$ peak from bulk $\mathrm{Zn}$ was recorded at $1021.6 \mathrm{eV}$ with peak width $1.9 \mathrm{eV}$ which matches well with the literature value [6]. In case of aligned $\mathrm{ZnO}$ NRs, the peak was seen to be shifted to $1022.1 \mathrm{eV}$ without changing the peak width as compared to bulk powder (Table 1).

The shift in binding energy is combination of two contributions, (i) true chemical shift of the level due to charge redistribution in process of chemical interaction and (ii) the shift due to the final state effects of the photoemission process. The shift in binding energy originating from the final state effects is explained in terms of relaxation energy involved in the process. In the photoemission process, the holes created undergo relaxation by recombining with electrons. During this process, the kinetic energy of the outgoing electron is influenced by the screening effect of the hole. It has been observed that when the cluster size $\sim 5 \mathrm{~nm}$, the relaxation is too significant to give a remarkable increase in binding energy compared to bigger clusters, as observed in case of $\mathrm{Ag}$ nanoparticles $[7,8]$. In the presence of large number of atoms in bulk $\mathrm{ZnO}$, the relaxation effect is smeared out. On the other hand, the effect is prominent with less number of electrons involved in the screening of the holes created in the photoemission process for nanosized crystal.

The shift in binding energy in ZnO NRs assembly compared to bulk $\mathrm{ZnO}$ carries important information. In the work by Radnik et al. [9] on Au nanoparticles, it was indicated that nanostructures of the order of 3-5 nm undergo relaxation effects. $\mathrm{ZnO}$ NRs are known to grow in spirality by attachment of nanotips of dimension below $5 \mathrm{~nm}$ [10]. In the present case, the end of the nanorods are expected to have isolated nanotips on each nanorods. The photoelectron signal from the NRs is basically contributed from these tips $\sim 5 \mathrm{~nm}$ [5]. It is right to say that majority of photoelectrons are coming from the mean free path depth of $\mathrm{Zn} 2 \mathrm{p}_{3 / 2}$ electrons which is of the order of $2 \mathrm{~nm}$ [9]. When the cluster size is of the order of 5 nanometers, the shift due to relaxation energy dominates very much compared to that in the bulk $\mathrm{ZnO}$. This resulted in a reduced kinetic energy of the outgoing photoelectrons which resulted in an increase in binding energy. The narrow peak width of the $\mathrm{Zn} 2 \mathrm{p}_{3 / 2}$ signifies the uniform size of the nanotips of the rods.

Determination of Auger parameter was observed to be a useful tool to find stoichiometry of the surface of oxides $[11,12]$. In Table 1, the modified Auger parameter of the NRs is shown and is compared with the bulk value of $\mathrm{ZnO}$. The modified Auger parameter was seen at $2010.4 \mathrm{eV}$ which is exactly matching with the value for bulk $\mathrm{ZnO}$ [6]. This indicates the formation of stoichiometric $\mathrm{ZnO}$ in the nanotubes even at the surface of NRs.

It is observed that though the relaxation energy of around $0.5 \mathrm{eV}$ is developed in the photoemission process due to particle size, the effect has no contribution to the value of the Auger parameter. It has been observed earlier in case of $\mathrm{Ag}$ nanoparticles [13] that the change in binding energy due to change in the particle size also leads to the change in Auger peak energy [13]. In the present case, it is also expected that there is a corresponding negative shift in Auger kinetic energy in the relaxation process which nullifies the size effect on Auger parameter.

The importance of determination of Auger parameter is lying in the interpretation of O1s peak. In Figure 3, the O1s peak acquired from $\mathrm{ZnO} \mathrm{NRs}$ is shown and is compared with bulk $\mathrm{ZnO}$. The O1s peak at $529.9 \mathrm{eV}$ contributed to the $\mathrm{O}^{-}$ions in the $\mathrm{ZnO}$ lattice and is surrounded by $\mathrm{Zn}$ ions and hence indicates the bonding of $\mathrm{ZnO}$. The higher energy peak at $531.9 \mathrm{eV}$ has been observed earlier [1416] and has been interpreted as defect oxygen [14] or the oxygen containing surface contaminants [16]. However, 


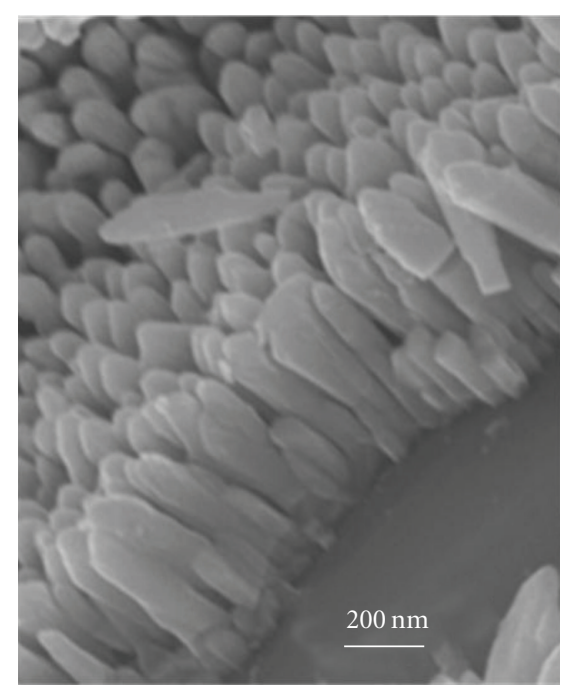

(a)

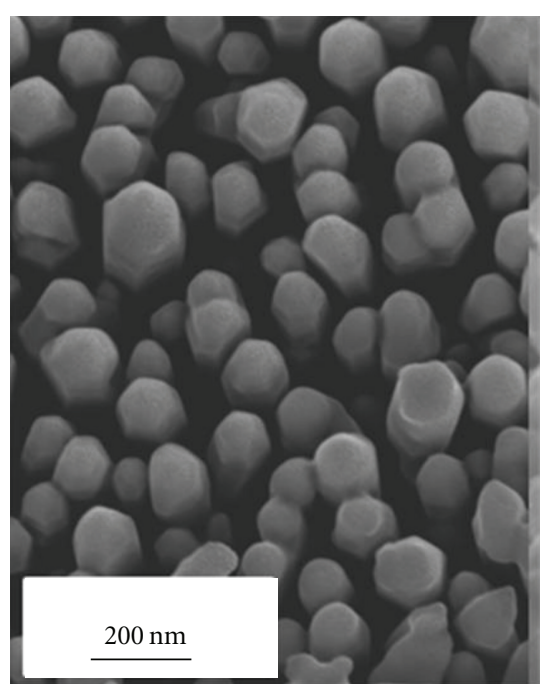

(b)

Figure 1: FESEM image of aligned ZnO NRs with diameters $\sim 100 \mathrm{~nm}$ in different orientations.

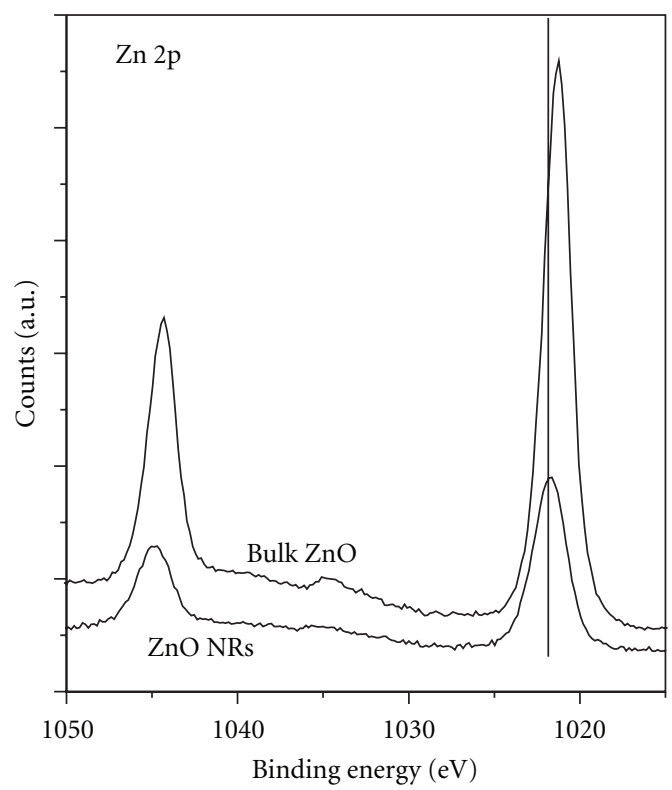

Figure 2: $\mathrm{Zn} 2 \mathrm{p}_{3 / 2}$ photoelectron spectra obtained from bulk $\mathrm{ZnO}$, and aligned NRs.

the Auger parameter value strongly denies the presence of $\mathrm{O}$ defect sites at the surface. In general, the surface $-\mathrm{OH}$ may contribute to the peak at this binding energy which indicates the presence of adsorbed hydroxide or surface contamination [16]. As XPS technique includes belowsurface information also, it may appear that the $-\mathrm{OH}$ might have originated from the bulk of $\mathrm{ZnO} \mathrm{NRs}$, but an information depth $\sim 2-3 \mathrm{~nm}$ with probe energy of $\mathrm{Al} \mathrm{K} \mathrm{K}_{\alpha}$ $(1486.6 \mathrm{eV})$ can be considered as surface where the presence of $-\mathrm{OH}$ groups are postulated. We can also state here that XRD of the sample did not show any phase other than the $\mathrm{ZnO}[5]$.

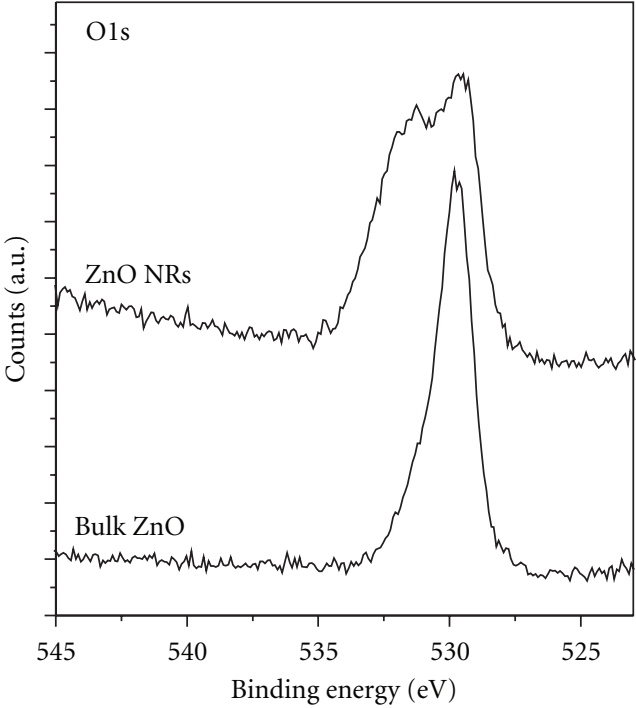

FIGURE 3: O 1s photoelectron spectra obtained from bulk $\mathrm{ZnO}$, and aligned NRs.

\section{Conclusions}

In conclusion, the binding energy of $\mathrm{Zn} 2 \mathrm{p}_{3 / 2}$ photoelectrons from $\mathrm{ZnO}$ NRs showed a significant shift in binding energy compared to its bulk value. The shift in binding energy is attributed to the presence of nanotips on the rods of size $\sim 5 \mathrm{~nm}$. The Auger parameter value, however, was not changed in NRs indicating the formation of stoichiometric $\mathrm{ZnO}$ nanorods.

\section{Acknowledgments}

The authors thank J.-J. Wu of Cheng Kung University, Taiwan for supplying the sample. They also thank M. Kamruddin and P. Sahoo for their contributions in FESEM studies. 


\section{References}

[1] J. C. Johnson, H. J. Choi, K. P. Knutsen, R. D. Schaller, P. Yang, and R. J. Saykally, "Single gallium nitride nanowire lasers," Nature Materials, vol. 1, no. 2, pp. 106-110, 2002.

[2] M. H. Huang, S. Mao, H. Feick et al., "Room-temperature ultraviolet nanowire nanolasers," Science, vol. 292, no. 5523, pp. 1897-1899, 2001.

[3] D. C. Reynolds, D. C. Look, B. Jogai, C. W. Litton, G. Cantwell, and W. C. Harsch, "Valence-band ordering in ZnO," Physical Review B, vol. 60, no. 4, pp. 2340-2344, 1999.

[4] B. Yan, R. Chen, W. Zhou et al., "Localized suppression of longitudinal-optical-phonon-exciton coupling in bent $\mathrm{ZnO}$ nanowires," Nanotechnology, vol. 21, no. 44, Article ID 445706, 2010.

[5] J. J. Wu and S. C. Liu, "Catalyst-free growth and characterization of ZnO nanorods," Journal of Physical Chemistry B, vol. 106, no. 37, pp. 9546-9551, 2002.

[6] C. D. Wagner, W. M. Riggs, L. E. Davis, J. F. Moulder, and G. E. Muilenberg, Handbook of XPS, Perkin Elmer Corporation, Eden Prairie, Minn, USA, 1979.

[7] P. Gangopadhyay, R. Kesavamoorthy, S. Bera et al., "Optical absorption and photoluminescence spectroscopy of the growth of silver nanoparticles," Physical Review Letters, vol. 94, no. 4, Article ID 047403, 2005.

[8] K. Luo, T. P. St Clair, X. Lai, and D. W. Goodman, "Silver growth on $\mathrm{TiO}_{2}(110)(1 \times 1)$ and $(1 \times 2)$," Journal of Physical Chemistry B, vol. 104, no. 14, pp. 3050-3057, 2000.

[9] J. Radnik, C. Mohr, and P. Claus, "On the origin of binding energy shifts of core levels of supported gold nanoparticles and dependence of pretreatment and material synthesis," Physical Chemistry Chemical Physics, vol. 5, no. 1, pp. 172-177, 2003.

[10] X. F. Zhou, Z. L. Hu, Y. Chen, and H. Y. Shang, "Microscale sphere assembly of $\mathrm{ZnO}$ nanotubes," Materials Research Bulletin, vol. 43, no. 10, pp. 2790-2798, 2008.

[11] R. Alfonsetti, L. Lozzi, M. Passacantando, P. Picozzi, and S. Santucci, "Determination of stoichiometry of SiOx thin films using an Auger parameter," Thin Solid Films, vol. 213, no. 2, pp. 158-159, 1992.

[12] L. Lozzi, M. Passacantando, P. Picozzi, and S. Santucci, "The use of the Auger parameter in the characterisation of some silicon compounds," Journal of Electron Spectroscopy and Related Phenomena, vol. 72, pp. 97-100, 1995.

[13] S. Bera, P. Gangopadhyay, K. G. M. Nair, B. K. Panigrahi, and S. V. Narasimhan, "Electron spectroscopic analysis of silver nanoparticles in a soda-glass matrix," Journal of Electron Spectroscopy and Related Phenomena, vol. 152, no. 1-2, pp. 91-95, 2006.

[14] J. H. Zheng, Q. Jiang, and J. S. Lian, "Synthesis and optical properties of flower-like $\mathrm{ZnO}$ nanorods by thermal evaporation method," Applied Surface Science, vol. 257, no. 11, pp. 5083-5087, 2011.

[15] H. Wang, S. Baek, J. Song, J. Lee, and S. Lim, “Microstructural and optical characteristics of solution-grown Ga-doped $\mathrm{ZnO}$ nanorod arrays," Nanotechnology, vol. 19, no. 7, Article ID 075607, 2008.

[16] S. Kaciulis, L. Pandolfi, E. Comini et al., "Nanowires of metal oxides for gas sensing applications," Surface and Interface Analysis, vol. 40, no. 3-4, pp. 575-578, 2008. 


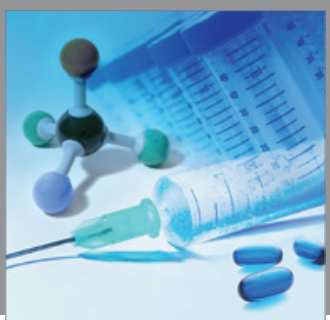

International Journal of

Medicinal Chemistry

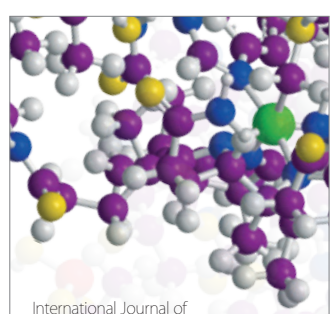

Carbohydrate Chemistry

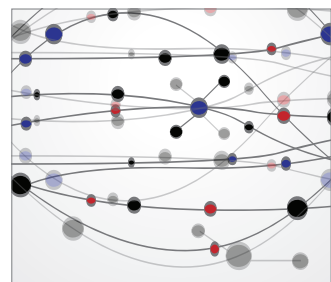

The Scientific World Journal
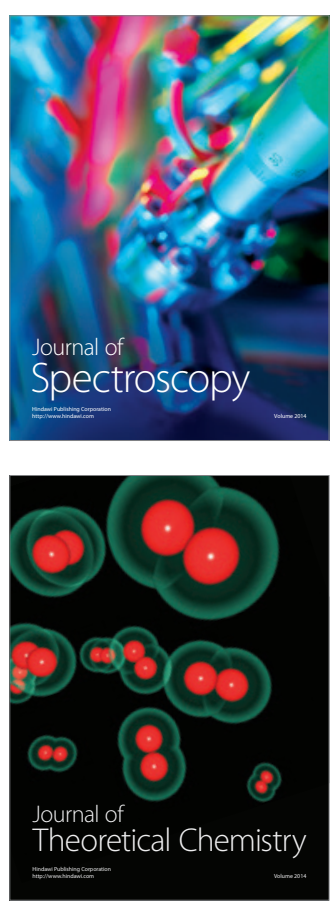
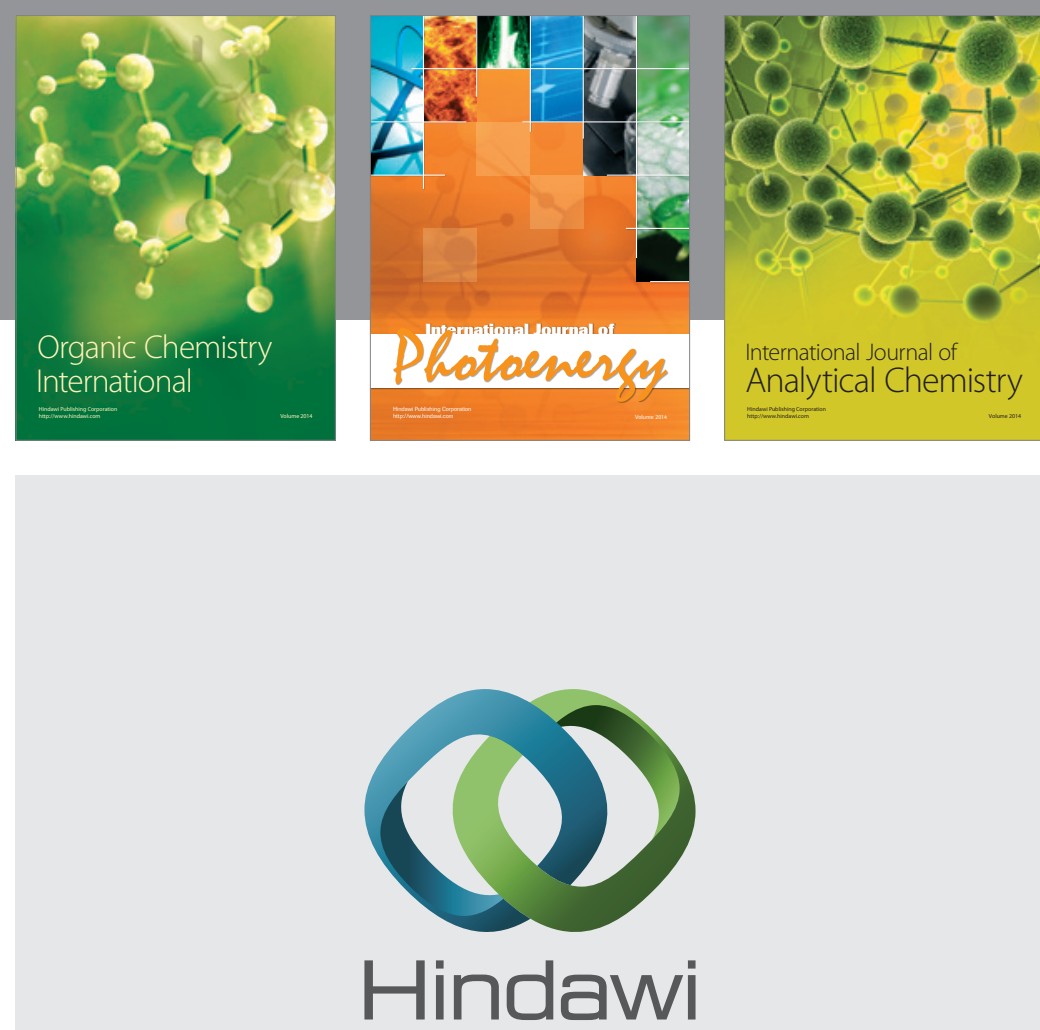

Submit your manuscripts at

http://www.hindawi.com
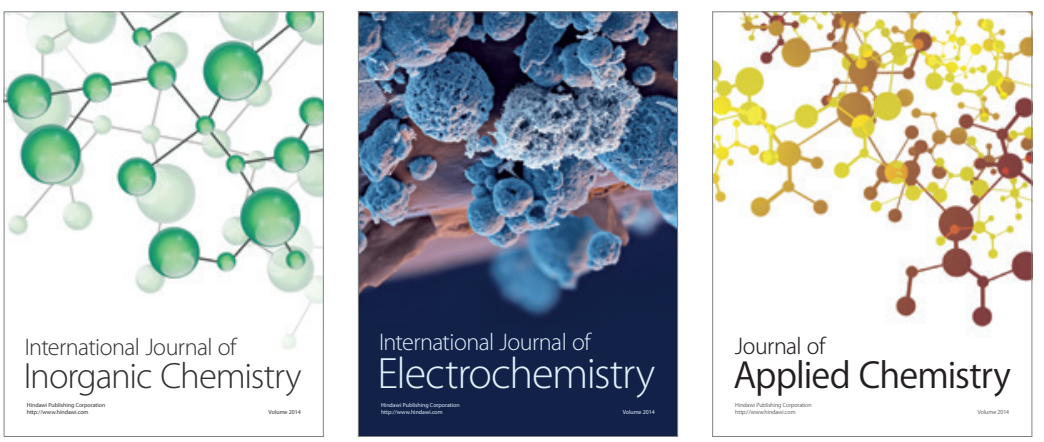

Journal of

Applied Chemistry
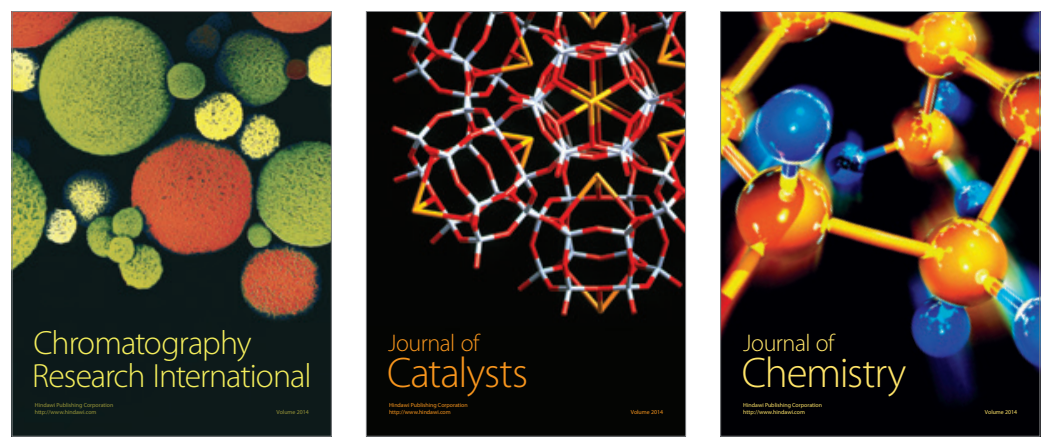
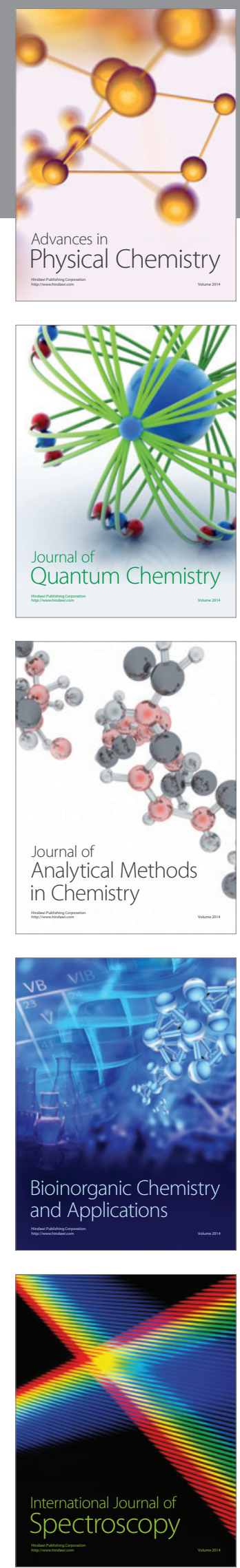